\title{
Evaluation of the effectiveness of early or delayed treatment upon healing of mandibular fractures: A retrospective study
}

Giath Gazal ${ }^{1}$

Correspondence: Dr. Giath Gazal

Email: gazal73@yahoo.co.uk
'Department of Oral and Maxillofacial Surgery, College of Dentistry, Taibah University, Almadinah Almunawwarah, Saudi Arabia

\section{ABSTRACT}

Objectives: This study was aimed to assess the impacts of delay treatment of mandibular fracture and its complications. In addition risk variables related such as time to repair, fracture types, substance abuse, causes, surgical management, muddling or complications and duration of clinic stay were also evaluated. Materials and Methods: The data of patients attending the Newcastle General Hospital, UK for the management of mandibular fractures were probed. This retrospective clinical trial conducted over 6 months, included 91 patients attending trauma operating theatre during weekdays or weekends. Data were analyzed for time to admission and treatment and its relationships to various factors using SPSS version 20 (SPSS Inc., Chicago, IL). Results: Time to treatment from the point of admission was $31.50 \pm 3.83 \mathrm{~h}$ during week days that has been significantly more for patients attending the hospital at weekends or nights. Similar trend was observed for total summative time from the incident to treatment analysis. Conclusions: This investigation has demonstrated that the rate of infection and postoperative complications following surgical treatment of mandible fractures can be eased off by reducing the waiting time from presentation to the emergency and to the operating theater.

Key words: Complications, delayed treatment, mandibular fracture

\section{INTRODUCTION}

The management of mandibular fractures may be tricky to make progress aesthetically and practically. A suitable administration is important to recreate and reproduce the structure, profile, form and function of uninjured status. ${ }^{[1]}$ Postoperative morbidity is a major disadvantage following oral and maxillofacial surgery. This includes pain, trismus, swelling and infection affecting patients' quality of life. ${ }^{[2]}$ Mandible is the main portable bone of the facial skeleton, and there has been a considerable upsurge in trauma and fracture in a majority of cases. ${ }^{[3-5]}$ In case if mandible fractures are not handles properly, that may prompt unfavorable outcome both cosmetically and functionally. ${ }^{[2,5]}$ The incidence of infection secondary to mandibular fractures ranges from $0 \%$ to $30 \%$, resulting in significant sequelae. ${ }^{[6]}$ A 5 years study by Gutta et al. ${ }^{[7]}$ was conducted to assess the causes of the complications associated with the surgical treatment of mandibular fractures at an academic tertiary hospital. The outcomes of Gutta study reported that the use of antibiotics did not decrease the incidence of infections. However, smokers and patients with systemic medical conditions had a greater risk of complications. Furthermore, a slight delay in surgical repair was not related to an increased complication rate. A study by Czerwinski et al. ${ }^{[6]}$ showed that the delay of mandibular fracture treatment $>3$ days does not significantly increase infection risk. On the other hand, repair should occur promptly after the injury.

A study by Pham-Dang et al. ${ }^{[8]}$ stated that the most maxillofacial fractures involve the mandible,

\footnotetext{
How to cite this article: Gazal G. Evaluation of the effectiveness of early or delayed treatment upon healing of mandibular fractures: A retrospective study. Eur J Dent 2015;9:87-91.

Copyright $\odot 2015$ Dental Investigations Society. DOI: $10.4103 / 1305-7456.149650$
} 
and there is an increasing trend in treating these fractures by osteosynthesis without intermaxillary fixation. Although treatment delays in the operative management of mandible fractures are often unavoidable, antibiotic prophylaxis associated with dental hygiene care can be indicated to prevent postoperative infections. The main mechanism of injury for mandible fractures is inconsistent in the literature. ${ }^{[9-15]}$ Maxillofacial fractures predominantly occur in young men, due to interpersonal violence. However, there is an increasing trend in falls as a cause of fracture, especially in female patients, consistent with the increasing trend in presentation of older people. ${ }^{[8,16-21]}$

Fewer studies have investigated the effectiveness of waiting timefrom presentation to accident and emergency until surgical intervention for patients with mandible fractures on the rate of infection and postoperative complications. ${ }^{[2,6-8]}$ There is presently no strong evidence for either acute or delayed treatment of mandibular fracture in order to minimize healing complications; new studies including a substantial number of cases treated on an acute basis are very much needed.

Primary aim of this study was to evaluate the effectiveness of early treatment of mandibular fractures upon healing and postoperative complications. The null hypothesis: Early or delayed treatment of mandibular fractures has no effect in reducing or increasing the postoperative complications.

\section{MATERIALS AND METHODS}

This study has been conducted using clinical data of patients attending the Newcastle General Hospital, UK for the management of mandibular fractures. The retrospective clinical study lasted for 6 months included 91 patients (14-60 years), who attended during weekdays 08.30-17.00 (treated at maxillofacial operating theater) and evenings (after 17.00) and weekends (treated at trauma operating theater). Patients presented with various types of fracture (single fracture, bilateral fracture, condyle fracture only, or multiple) required open reduction and internal fixation of fractured mandibles were included. The data were recorded including: Date of visit, hospital number, age and gender. The patient's relevant medical history was to be considered in relation to the patient's suitability for general anesthesia. Any patients having missing data or incomplete information were excluded from the study.
Patients were classified into three groups according to the time utilized from admission to operative intervention ( $<24$ [treated within $24 \mathrm{~h}$ ],$<72$ [treated within $72 \mathrm{~h}$ ] and $\geq 72$ [treatment took longer than $72 \mathrm{~h}$ ]). Different mechanisms of injury were also considered in relation to time consumed to treat patients. Common postoperative complications such as numbness, malocclusion and infection were recorded at 1 week and 4 weeks after patient's discharge date. A two group $t$-test with a 0.01 two-sided significance level was applied, and comparison between the groups was made using non parametric tests at a significance level of 0.01 . The golden time for treatment the mandible fractures was set up as follow.

Patients needing urgent treatment should be treated within $72 \mathrm{~h}$ (maxillofacial surgery ward). The risk of infection has not been observed to increase by delaying

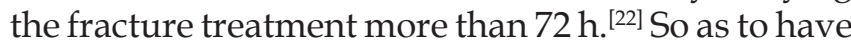
the capacity to offer better treatment, administration and forethought to these patients it crucial to study the nature of trauma and its different perspectives and categories, sort and sort them appropriately.

\section{RESULTS}

This study was based on collecting information from 93 patients' notes who were attending the Newcastle General Hospital, UK (Maxillofacial Surgery Department) for the management of mandibular fractures over the period of 6 months. The majority of patients $(>90 \%)$ were male patients [Figure 1] and presented with four major types of mandibular fractures. The simple (single or line fracture) was the main type contributing $52.69 \%$ of total cases, followed by bilateral fractures (39.78\%). Condylar and multiple fractures contributed only $7.53 \%$ whereas only one patient $(1.08 \%)$ reported condylar fractures.

The average time the patient took from incident to admission to the hospital was $11.20 \pm 0.68 \mathrm{~h}$ and there was no significant difference for incidence happened during the weekend or weekdays [Figure 2]. Time to treatment from the point of admission was $31.50 \pm 3.83 \mathrm{~h}$ during week days that has been significantly more than patients attending the hospital at weekends or nights. Similar trend was observed for total summative time from the incident to treatment analysis [Figure 2]. The treatment procedure took a prolonged time $(57.15 \pm 5.05 \mathrm{~h})$ for patients attending during working hours compared to patients attending over the weekends [Figure 2]. Considering the potential cause of injuries, alcohol abuse and related assault 
remain the most common cause $(61 \%$ all reported within 3 days of injury) followed by Interpersonal violence/assault that accounted for 22\% [Figure 3]. The fall and road traffic accidents (RTC) accounted for $11 \%$ and $7 \%$ respectively. Patients with mandible fractures related to RTC have higher median time to treatment from admission to operative intervention than other present complaints $[P<0.05$, Figure 3].

In terms of postoperative complications, a follow up of 4 weeks was recorded [Figure 4]. About $45 \%$ patient did not report any post-operative complication in 4 weeks follow up time. Whereas $40 \%$ of patients with fractured mandible reported numbness after 1 week however it was reduced to $22 \%$ in 4 weeks follow up. The third main complication was malocclusion that was developed in $17 \%$ and reduced to just $9 \%$ in later follow up. The incidence of postoperative infections was reported in 5\% patients and remains consistent for earlier and later follow ups.

\section{DISCUSSION}

The review of literature suggests that there is uniform consent that the typical patient with a mandibular fracture is male and between 14 and 60 years of age. ${ }^{[3]}$ The results of this study have revealed that $38 \%$ of

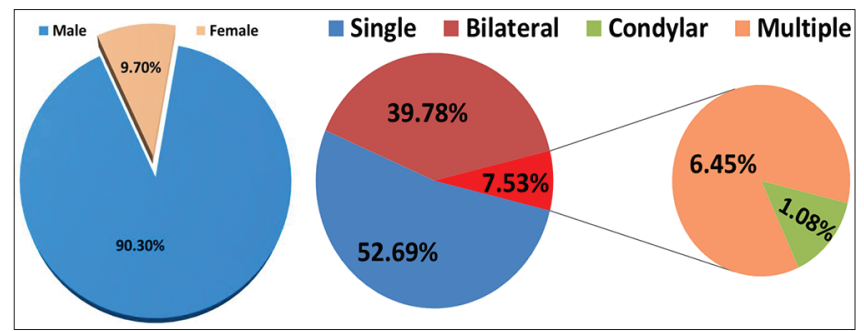

Figure 1: Patient distribution on the basis of gender and type of mandibular fractures

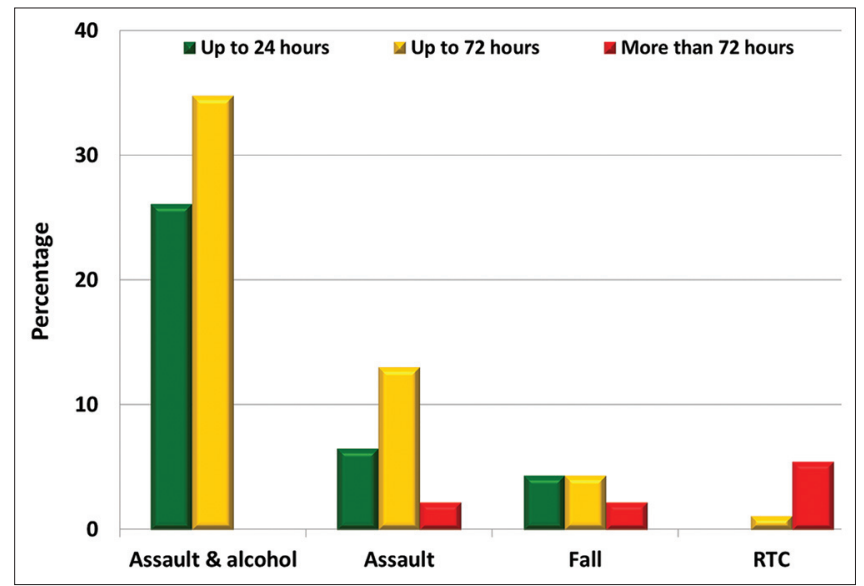

Figure 3: Relationships of fracture etiology and respective time to treatment for patient reporting mandibular fractures (road traffic cases) patients were treated $<24 \mathrm{~h}, 52 \%$ treated between $24 \mathrm{~h}$ and $72 \mathrm{~h}$ however only $10 \%$ treated $>72 \mathrm{~h}$. Secondly, the mechanism of trauma is due to violence that is a major cause to sustain a mandibular fracture. In consistent to several studies, which report very high rates of interpersonal violence with almost "epidemic proportions", all fractures were a consequence of the assault in the patient group. On the other hand, it must be pointed out that none of the cases involved a gunshot wound despite a very high percentage of privately owned small arms.

Instinctively, it might cause the postponement for mandible fracture treatment might prompt a higher complication rate. For sure, prior studies have indicated an association between prior treatment and diminished disease. Anderson and Alpert ${ }^{[23]}$ showed a $16 \%$ general postoperative infection rate in the investigation of 75 mandible fractures; however, no contaminations happened in patients operated on inside $24 \mathrm{~h}$ of trauma. An alternate study by

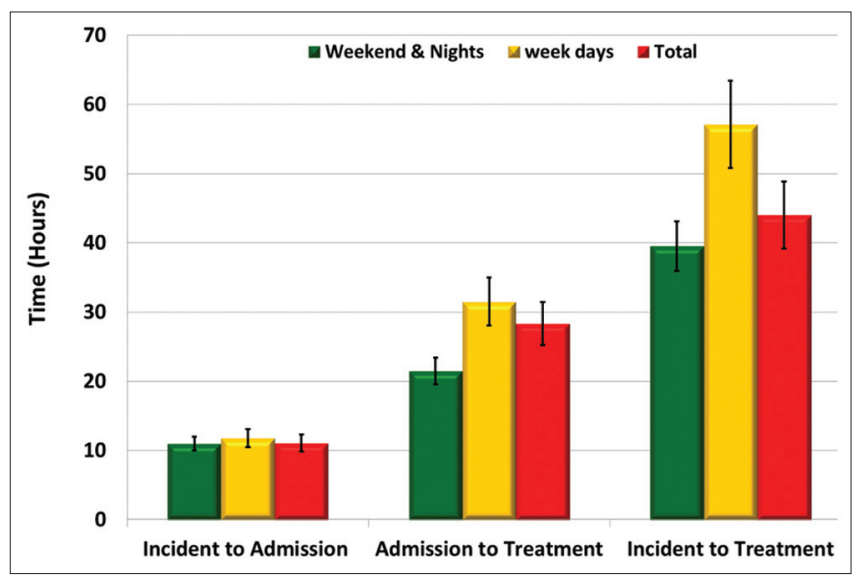

Figure 2: A record of time to treatment for mandibular fracture patients attending the hospital during office hours and out of office hours

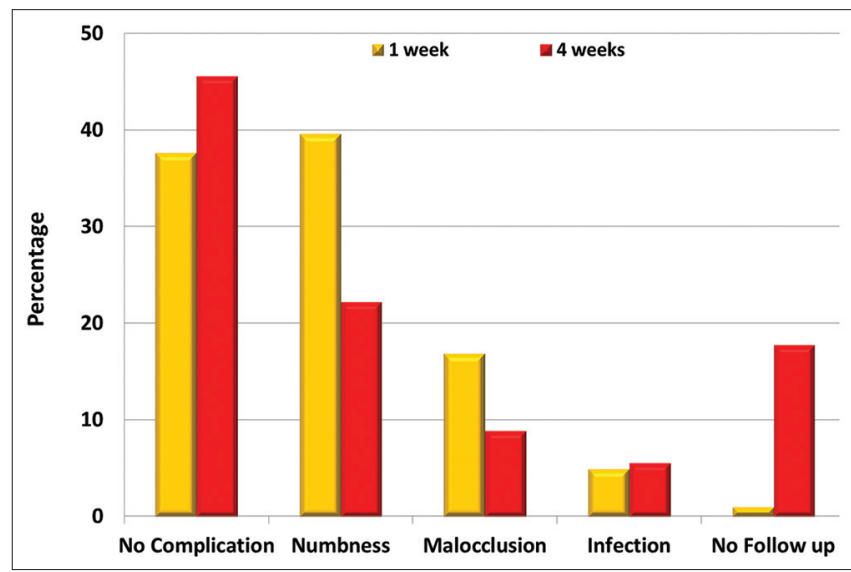

Figure 4: Postoperative follow up for incidence of complications in mandibular fracture patients 
Maloney et al. ${ }^{[24]}$ reported 204 fractures in 131 patients with an in overall infection rate of $4.4 \%$. In any case, consistent patients treated inside $72 \mathrm{~h}$ of injury and or trauma had no contaminations and infections. ${ }^{[24]}$ Of all the categories responsible for facial trauma in the present study, violence was the most prevalent, and when compared to the second most frequent category, automobile accidents, ${ }^{[25]}$ this association was statistically significant.

There was a significant increase in the median time to treatment from admission to surgical intervention for patients who treated in maxillofacial operating theatre comparing with those treated in Trauma Operating theatre. Patients with mandible fracture following road traffic collision (RCT) or association between alcohol intoxication and assault recorded higher median time to treatment as results of head injuries, chest Injury (rib fractures, hemothorax and pneumothorax).

Despite the fact that in the present study, in all trauma sort classifications there was a prevalence of men, women can likewise be casualties of trauma, particularly interpersonal roughness, on all its structures, and the majority of the times there are large amounts of alcoholic beverages included. The World Health Organization reports that violence is dependable for the high health insurance takes and for about 73,000 death/year in Europe. ${ }^{[26]}$ Postoperative complications for the mandibular fractures management are fundamentally connected to the severity of the fracture instead of the treatment plan. ${ }^{[24]}$ Regarding the relationship of trauma mechanism and fracture site, our study confirms previous findings of a correlation between etiology and fracture pattern. The fracture classification was similar to those found in previous studies. Considering the comparable low number of traffic and occupational related injuries in our study, the safety measurements in these fields seem to have proven their effectiveness in the prevention of facial injuries.

Patients conceded from the Emergency Department for prompt repair were frequently put off because of operating room intervals for absence of employees/ work force or more intense cases requiring urgency. This prompts more hospital admissions and expanded expenses. ${ }^{[27-30]}$ Elective repair takes into consideration a brief hospital admission and in addition utilization of surgical facilities, which might be better financially savvy than performing surgery at a Tertiary Care Centers. Delay from admission to treatment may be because of the patient's condition at time of presentation. The delay from admission to treatment may be because of elective theatre (Maxillofacial Theater weekdays 9 am to $5 \mathrm{pm}$ ). Most patients were delayed after presentation due to lack of theatre time.

\section{CONCLUSIONS}

This investigation has demonstrated that the rate of infection and postoperative complications following surgical treatment of mandible fractures can be eased off by reducing the waiting time from presentation to the emergency and to the operating theatre. The risk of infection, malocclusion, mal-union and technical complications might rise with treatment delay, and therefore the surgical team must be alert of these consequences when reducing these fractures.

\section{ACKNOWLEDGMENTS}

Authors would like to thank Oral and Maxillofacial Department technical staff at Newcastle General Hospital, Newcastle, UK for technical support and assistance.

\section{REFERENCES}

1. Butler DJ, Moffic HS, Turkal NW. Post-traumatic stress reactions following motor vehicle accidents. Am Fam Physician 1999;60:524-31.

2. Ristow O, Pautke C, Kehl V, Koerdt S, Hahnefeld L, Hohlweg-Majert B. Kinesiologic taping reduces morbidity after oral and maxillofacial surgery: A pooled analysis. Physiother Theory Pract 2014;30:390-8.

3. Ellis E $3^{\text {rd }}$, el-Attar A, Moos KF. An analysis of 2,067 cases of zygomatico-orbital fracture. J Oral Maxillofac Surg 1985;43:417-28.

4. Nanci A. Ten Cate's Oral Histology: Development, Structure, and Function. $8^{\text {th }}$ ed. St. Louis, Mo, London: Mosby; 2012.

5. Bataineh AB. Etiology and incidence of maxillofacial fractures in the north of Jordan. Oral Surg Oral Med Oral Pathol Oral Radiol Endod 1998;86:31-5.

6. Czerwinski M, Parker WL, Correa JA, Williams HB. Effect of treatment delay on mandibular fracture infection rate. Plast Reconstr Surg 2008;122:881-5.

7. Gutta R, Tracy K, Johnson C, James LE, Krishnan DG, Marciani RD. Outcomes of mandible fracture treatment at an academic tertiary hospital: A 5-year analysis. J Oral Maxillofac Surg 2014;72:550-8.

8. Pham-Dang N, Barthélémy I, Orliaguet T, Artola A, Mondié JM, Dallel R. Etiology, distribution, treatment modalities and complications of maxillofacial fractures. Med Oral Patol Oral Cir Bucal 2014;19:e261-9.

9. Lee KH. Epidemiology of mandibular fractures in a tertiary trauma centre. Emerg Med J 2008;25:565-8.

10. Kieser J, Stephenson S, Liston PN, Tong DC, Langley JD. Serious facial fractures in New Zealand from 1979 to 1998. Int J Oral Maxillofac Surg 2002;31:206-9.

11. Schön R, Roveda SI, Carter B. Mandibular fractures in Townsville, Australia: Incidence, aetiology and treatment using the $2.0 \mathrm{AO} / \mathrm{ASIF}$ miniplate system. Br J Oral Maxillofac Surg 2001;39:145-8.

12. Allan BP, Daly CG. Fractures of the mandible. A 35-year retrospective study. Int J Oral Maxillofac Surg 1990;19:268-71.

13. Oikarinen K, Schutz P, Thalib L, Sándor GK, Clokie C, Meisami T, et al. Differences in the etiology of mandibular fractures in Kuwait, Canada, and Finland. Dent Traumatol 2004;20:241-5.

14. Fridrich KL, Pena-Velasco G, Olson RA. Changing trends with mandibular fractures: A review of 1,067 cases. J Oral Maxillofac Surg 1992;50:586-9.

15. King RE, Scianna JM, Petruzzelli GJ. Mandible fracture patterns: A 
suburban trauma center experience. Am J Otolaryngol 2004;25:301-7.

16. Depprich R, Handschel J, Hornung J, Meyer U, Kübler NR. Causation, therapy and complications of treating mandibular fractures-A retrospective analysis of 10 years. Mund Kiefer Gesichtschir 2007;11:19-26.

17. Ingole PD, Garg A, Shenoi SR, Badjate SJ, Budhraja N. Comparison of intermaxillary fixation screw versus eyelet interdental wiring for intermaxillary fixation in minimally displaced mandibular fracture: A randomized clinical study. J Oral Maxillofac Surg 2014;72:958.e1-7.

18. Gazal G, Mackie IC. A comparison of paracetamol, ibuprofen or their combination for pain relief following extractions in children under general anaesthesia: A randomized controlled trial. Int J Paediatr Dent 2007;17:169-77.

19. Thorén H, Schaller B, Suominen AL, Lindqvist C. Occurrence and severity of concomitant injuries in other areas than the face in children with mandibular and midfacial fractures. J Oral Maxillofac Surg 2012;70:92-6.

20. Yates D, Aktar R, Hill J, Guideline Development Group. Assessment, investigation, and early management of head injury: Summary of NICE guidance. BMJ 2007;335:719-20.

21. Mills K. Guest editorial: Trauma and its link to substance use. Of substance: The national magazine on alcohol. Tob Other Drugs 2010;8:2.

22. Biller JA, Pletcher SD, Goldberg AN, Murr AH. Complications and the time to repair of mandible fractures. Laryngoscope 2005;115:769-72.

23. Anderson T, Alpert B. Experience with rigid fixation of mandibular fractures and immediate function. J Oral Maxillofac Surg 1992;50:555-60.

24. Maloney PL, Welch TB, Doku HC. Early immobilization of mandibular fractures: A retrospective study. J Oral Maxillofac Surg 1991;49:698-702.
25. Choi KY, Yang JD, Chung HY, Cho BC. Current concepts in the mandibular condyle fracture management part I: Overview of condylar fracture. Arch Plast Surg 2012;39:291-300.

26. World Health Organization. Global Status Report on Alcohol 2004. Geneva. World Health Organization; 2004.

27. Daif ET. Correlation of plates' number with complications of osteosynthesis in mandibular fractures. J Craniofac Surg 2014; 25: 526-9.

28. David LR, Bisseck M, Defranzo A, Marks M, Molnar J, Argenta LC Cost-based analysis of the treatment of mandibular fractures in a tertiary care center. J Trauma Inj Infect Crit Care 2003;55:514-7.

29. Halicioglu K, Celikoglu M, Buyuk SK, Sekerci AE, Candirli C. Effects of early unilateral mandibular first molar extraction on condylar and ramal vertical asymmetry. Eur J Dent 2014;8:178-83.

30. Celikoglu M, Unal T, Bayram M, Candirli C. Treatment of a skeletal Class II malocclusion using fixed functional appliance with miniplate anchorage. Eur J Dent 2014;8:276-80.

\begin{tabular}{|l|l|}
\hline \multicolumn{2}{|c|}{ Access this article online } \\
\hline Quick Response Code: & Website: \\
& www.eurjdent.com \\
\cline { 2 - 2 } & $\begin{array}{l}\text { Source of Support: Newcastle General } \\
\text { Hospital. } \\
\text { Conflict of Interest: None declared }\end{array}$ \\
\hline
\end{tabular}

